\title{
EDUCAÇÃO: A RESPEITO DA ESCOLA SEM PARTIDO
}

\section{ARTIGO ORIGINAL}

MACHADO, Marcos Antonio Dimas ${ }^{1}$

MARQUES, Edmilson Ferreira ${ }^{2}$

MACHADO, Marcos Antonio Dimas. MARQUES, Edmilson Ferreira. Educação: A respeito da Escola sem Partido. Revista Científica Multidisciplinar Núcleo do Conhecimento. Ano 06, Ed. 01, Vol. 05, pp. 92-106. Janeiro de 2021. ISSN: 24480959, Link de acesso: https://www.nucleodoconhecimento.com.br/educacao/respeitoda-escola

\section{RESUMO}

É possível existir uma escola onde o professor não doutrine seus alunos, uma vez que, o objetivo da educação é exatamente esse, moldar nossas crianças conforme os padrões impostos pela sociedade? Seria então possível existir uma escola realmente sem partido, tendo em vista que a educação é uma instituição estatal? Neste trabalho buscamos demonstrar que a educação é uma forma de socializar a criança e para tanto, é preciso ir aos poucos lapidando esse indivíduo até o ponto em que ele seja inserido na sociedade e tenha autonomia. Partiremos da sistematização da educação na Grécia Antiga, faremos alusões à determinados fatos no decorrer da história para demonstrar o processo educacional, diferenciando a educação da escolarização e

\footnotetext{
${ }^{1}$ Licenciatura Plena em Filosofia Faculdade Serra da Mesa - FaSeM, Uruaçu - Go., Teologia Eclesiástica Faculdade Gospel - Curso livre EAD., Licenciatura em História Unicesumar - Sorriso, MT., Especialista no Ensino de História Universidade Estadual de Goias, Uruaçu - GO.

2 Orientador. Doutorado em História. Mestrado em História. Especialização em Ciência Política. Graduação em História.
} 
suas respectivas finalidades, observando a valorização de uma, em detrimento da outra.

Palavras-chaves: Educação, escolarização, doutrinação, escola sem partido.

\section{INTRODUÇÃO}

Diante dos problemas apresentados na educação, quanto a questão de doutrinação por parte de alguns professores, seja no ensino fundamental ou ainda, no ensino médio e até curso superior, e, a respeito do movimento "Escola sem partido", foi desenvolvido esse artigo com a finalidade de buscar conhecer ao longo da história da educação, se é possível ou não haver uma Escola sem partido e ainda, se por um acaso pode haver uma educação em que o professor não esteja, de certa forma, doutrinando seus alunos, seja para o lado da dita "direita" ou para o lado da dita "esquerda" nacional, as quais polarizaram o Brasil.

A partir da inquietação, se há possibilidade de existir um ambiente de ensino onde não predomine uma ideologia, podemos perguntar se o controle social sempre esteve permeando o processo educacional, com a finalidade de "modelar" os indivíduos para viverem em sociedade.

Para tanto, cabe verificar num primeiro momento o que vem a ser a educação e se essa é uma só. Depois de analisarmos esse ponto, é preciso ainda compreender como é o processo educacional e sua finalidade no decorrer do tempo histórico e se a educação é necessária e se essa deve dar às ciências exatas e a às ciências da natureza uma supervalorização em detrimento das ciências humanas. Em meio a tais questões, é relevante compreender o meio que o homem vive, a partir do qual, perde sua animalidade e alcança a humanidade. Além disso, entender o papel que a família tem no processo de formação da criança para a sociedade, pois desse ponto de vista, a educação não passaria de uma convenção social, na qual o professor teria um papel predominante para a formação da razão do sujeito, tendo em vista que este é um animal especializado em cérebro, segundo Battista Mondin (1980). 


\section{O QUE VEM A SER EDUCAÇÃO}

Para tanto, é necessário partirmos da Grécia Antiga, pois, nenhuma sociedade pode chegar ao seu amadurecimento e à perpetuação de sua existência, sem se entregar à educação, tendo em vista que isso a levaria à não padronização ou normatização do seu estilo de vida, o que chamamos de cultura.

Por educação, podemos entender o conceito de tradição, sendo que por meio dela podemos transmitir à geração mais nova aquilo que aprendemos das gerações anteriores à nossa conforme Durkheim (2011). Educação pode também ser entendida como cultura[3], que segundo Mondin (1980), num sentido pedagógico seria o cultivo do homem, levando-o ao amadurecimento e à formação da sua personalidade. Essa personalidade é construída por meio das personalidades formadas anteriormente por outras gerações e depois deve ser aplicada nos indivíduos da geração posterior. Assim, segundo Durkheim (2007), comunidades[4] e sociedades[5] anteriores à nossa, foram formadas e "enformadas" conforme a cultura antropológica[6] específica de cada uma delas.

Para os gregos atenienses, a educação deveria ser aplicada com a finalidade de formar para o trabalho (tèchné[7]), mas também para a vida em sociedade (ethos[8]). Os gregos podem ser considerados os precursores de toda a cultura sistematizada existente no mundo atual. Dessa forma, pode-se dizer que os gregos dominaram o mundo por meio da sabedoria (filosofia). Esse exemplo de um povo que valorizou a educação, perpetuou sua existência e como eles acreditavam, adquiriram a imortalidade, como é atribuído a Sócrates o dizer que "a alma de todo homem é imortal, mas a alma do justo é imortal e divina."

Com isso, os gregos buscavam aprender e praticar o ethos para que pudessem não só se imortalizar suas almas, mas também se divinizar na eternidade. Os gregos atenienses conseguiram se eternizar por meio da educação, chegando até nossos dias por meio do nosso alfabeto e da origem das nossas palavras, as quais são na maioria grega ou romana (latim). No entanto, podemos ver na história que sempre que um povo se dá à busca da riqueza e empoderamento, deixando de lado a formação 
do homem como um todo (técnico e moral), eles entraram em decadência e seu povo e território começaram a reduzir e em casos extremos, a desaparecerem.

O homem pode ser educado de duas formas, pela instrução, que segundo Kant (1999) "transforma a animalidade do homem em humanidade", onde esse homem é moldado conforme a vontade da sociedade a qual ele esteja inserido, pois é por meio da instrução que o homem vai aprendendo, por meio da polidez[9], a andar, falar, a cuidar de si mesmo e assim por diante, até chegar em seu amadurecimento, o que seria a autonomia[10] da razão. E a segunda, seria a disciplina, a qual seria uma forma de ensinar por meio da punição ou castigo, ou ainda, sofrimento através da própria experiência. A sociedade precisa então, extrair dela mesma suas capacidades para tornar o sujeito um verdadeiro homem, o que, ainda conforme Kant (1999)só acontece por meio da educação, que seria então, a socialização da criança dentro dos padrões da sociedade, "forçando-a" a se adequar à cultura estabelecida. Segundo Kant,

A educação é uma arte, cuja prática necessita ser aperfeiçoada por várias gerações. Cada geração, de posse dos conhecimentos das gerações precedentes, está sempre melhor aparelhada para exercer uma educação que desenvolva todas as disposições naturais na justa proporção e de conformidade com a finalidade daquelas, e, assim guie toda a humana espécie a seu destino. (KANT,1999, p. 19).

A tradição deve estar presente na sociedade para que esta possa, a partir dos conhecimentos já recebidos e conquistados, evoluir, dando um salto ainda maior que o da geração anterior, se preparando para repassar o conhecimento adquirido e evoluído para a geração posterior, para que ela possa também, a partir do conhecimento já herdado, evoluir-se, e assim sucessivamente.

Então, o homem poderá aprender com a memória das gerações anteriores, extraindo delas aquilo que de ruim e de errado ela tenha passado, para que não tenha que experienciar o mal sofrido ou praticado por seus antecessores, podendo se desenvolver sem ter que pagar o preço que seus antepassados. Então, uma geração vai formando a outra por meio de suas experiências e conhecimentos adquiridos e modelando-a conformo suas necessidades e intenções político-sociais. A isso chamamos de educação. 


\section{O PROCESSO EDUCACIONAL E SUA FINALIDADE}

Uma questão a ser levantada seria então, se há influência da educação sobre a sociedade, ou se é a sociedade que influencia a educação. Na verdade essa questão é uma via de mão dupla. Se analisarmos, por exemplo, a consciência coletiva de Durkheim (2007), o indivíduo se perde em meio às leis, regras e normas sociais, préestabelecidas na sociedade e que a educação deve ensinar para seus discentes a viverem, não seu individualismo mas o coletivismo, para que esses possam por meio da disciplina e instrução se socializarem para um bom convívio. Veremos, deste ponto de vista, que a educação forma a sociedade e que a sociedade impõe o que deve ser ensinado às suas crianças e jovens.

Contudo, há de se entender que existem diferenças nos dias atuais entre as definições de educação e escolarização. Educação tem perdido o sentido e o valor no meio social e muitas vezes tem sido deixada de lado no processo de formação do indivíduo, pois entende-se a educação como a formação do ethos grego, ou seja, o conjunto de normas, crenças e valores para o bom convívio social (moral). Já a escolarização nos leva para o lado da tèchné, que seria a formação para o mercado de trabalho, fortalecendo assim o cientificismo[11], em detrimento dos demais conhecimentos[12] e finalidades.

Desde então, a educação tem tomado ares de escolarização, com a finalidade de formar trabalhadores para ocuparem vagas no mercado de trabalho. A escolarização, dessa forma, se sobressai à educação, que tem se tornado uma coisa sem significado prático, e com isso, a sociedade tem enfrentado sérios problemas políticos sociais. Caso se faça uma pesquisa em sala de aula, possivelmente chegaremos a uma conclusão de que uma grande maioria dos alunos querem estudar e se escolarizar, não para fazer o que gostam, mas para terem um bom lugar no mercado de trabalho, se preocupando com o status[13], a economia[14] e a política[15] dentro da sociedade.

Não poderia tomar partido aqui e puxar para o lado da educação da comunidade ou para a sociedade industrial. Porém podemos ver que esta, tem um certo predomínio sobre aquela. A educação tem sido um objeto ou melhor, um meio para que a 
sociedade possa alcançar seus objetivos, como podemos analisar em qualquer Plano Político Pedagógico (P.P.P.), tanto das escolas públicas, quanto das privadas, que a finalidade da educação é "Inserir o jovem com aproveitamento no mercado de trabalho". Essa colocação é extraída da Lei de Diretrizes e Bases da Educação (LDB) art. 214 §IV que diz, "formação para o trabalho".

Assim, a educação perde lugar para a escolarização, tornando-se tecnicista, com um objetivo de formar trabalhadores, visto que toda matéria escolar como matemática, português (literatura, redação e gramática), química, física, biologia, têm se voltado como meio de conduzir nossas crianças ao mercado de trabalho. Com isso, matérias como história, filosofia, sociologia, geografia, artes, educação física e ensino religioso, têm sido menosprezadas por entenderem que elas não contribuem para uma lucrativa formação profissional, e que serviriam apenas como matérias auxiliadoras àquelas tidas como práticas e utilitaristas. Tudo isso, para uma sociedade capitalista.

No entanto, esquecem-se que no mesmo art, $214 \S$ V se lê, "promoção humanística (grifo meu), científica e tecnológica do País;". Essa promoção humanística tem sido deixada de lado como educação e tem-se dado mais ênfase à "científica e tecnológica do País" (escolarização). E como dito anteriormente, se um povo não valorizar sua educação, esse tende a diminuir e em casos extremos desaparecer. Fica então uma questão, menosprezando a educação não estaríamos regredindo ao invés de estarmos evoluindo? Poderia um país desenvolver-se cientificamente e tecnologicamente sem se desenvolver humanisticamente? Não somos, ao menos ainda, uma sociedade de inteligências artificiais, mas somos seres humanos que carecemos de uma formação para perdemos, segundo Kant (1999), a nossa animalidade para dar lugar à nossa humanidade, o que só pode acontecer por meio da educação e nunca por meio da escolarização.

Agora, parafraseando Karl Marx (2011), esta colocação não se trata de um problema teórico como alguns podem pensar, mas pelo contrário, é uma questão prática, pois, como dito anteriormente, nossos alunos querem se formar para ocupar as melhores posições no mercado de trabalho. Partindo da realidade da qual a educação está inserida podemos chegar à verdade de que esses alunos nascem, crescem e se 
desenvolvem numa sociedade capitalista, sendo induzido e alienado a todo o instante ao consumismo, não tomando conhecimento da sua situação (consciência de classe), mas acreditando que está vivendo em uma sociedade dita normal, pois desde o seu nascimento ele vive dessa forma e não conheceu outras vertentes dos meios sociais de produção.

É na prática que o homem deve demonstrar a verdade, isto é, a realidade e o poder, a força de seu pensamento. A disputa em torno da realidade ou irrealidade do pensamento - isolado da prática - é um problema puramente escolástico. (MARX e ENGELS, 2011, p. 41).

Por esse motivo, não podemos nos deter a uma construção teórica, como fazem os filósofos, não que sejam errados, mas como acreditava Marx (2011), é a circunstância em que vive o homem que irá contribuir para formar sua própria razão. Sendo assim, quanto a essa construção sobre o valor da educação na sociedade, poderá haver muitas opiniões, mas lembremos que Marx acreditava que a consciência era criada no indivíduo conforme o meio em que este vivia. Por isso, se alguém foi escolarizado, logicamente não concordará com estas colocações, porém, a pessoa que recebeu educação e escolarização (formação), abraçará estas colocações por saber, por meio da prática e não da teoria, o que é viver em uma sociedade capitalista.

Desta forma, se buscarmos a opinião dos proletários que tenham consciência de classe quanto à questão do modo de produção, ele terá uma opinião antagônica à do burguês que defenderá esse modo de produção. Assim, uma pessoa apenas escolarizada, obviamente defenderá que a educação humana deve se curvar ante a escolarização. Porém, uma pessoa educada, defenderá essa educação por conhecer a eficiência e o bem que esta causa na sociedade, formando o homem por completo.

Temos que conhecer os processos históricos dos nossos antepassados, para entender os processos políticos/sociais da atualidade e, a partir de então, construirmos nossa própria história, nos preparando para repassar o conhecimento para a geração posterior. Desta forma, nunca partiremos da "estaca zero" do conhecimento e estaremos sempre, como seres humanos, partindo de conhecimentos 
já postos, podendo desenvolver ainda mais esses conhecimentos. Eis então, uma das outras muitas importâncias de se estudar história.

Interessante é que não se vê com frequência ou com certa constância, as indagações de "por que estudar Português?" Ou Matemática? Entre outras mais. Pois, essas têm utilidade para a formação de trabalhadores, que ocuparão o mercado de trabalho, e muitas vezes o trabalho predominantemente braçal. o trabalho predominantemente intelectual a maioria dos alunos não têm acesso, sendo que a escolarização oferecida pelo governo não oferece a qualidade suficiente para que possam ingressar nas Universidades Públicas, uma vez que estudam apenas o básico para poderem ser "inseridos com aproveitamento no Mercado de trabalho" e não para ter uma formação humana por completo (educação mais escolarização).

A escolarização está, então, voltada para o tecnicismo, mesmo que o curso oferecido não seja técnico, mas tem a finalidade de inserir o jovem no mercado de trabalho. Logo, de certa forma, o próprio governo, representado pelo Ministério da Educação (MEC), tem contribuído para a desvalorização do ensino das ciências humanas, as quais prestam um serviço de formação dos cidadãos dotados de direitos e deveres. $A$ História, neste caso, vem sofrendo ao longo do tempo afrontamentos, assim como as demais ciências humanas.

Estamos certos de que, nos tempos em que vivemos poderão e até deve existir colocações diferentes desse artigo, pois bem sabemos que a sociedade vive polarizada, onde as pessoas que acreditam no liberalismo, seja ele político ou econômico, defenderão que não se deva ensinar sobre outros modos de produção, como temos visto que um professor/professora ao ensinar sobre o socialismo e o comunismo fica taxado como doutrinador. Porém, as pessoas que acreditam no socialismo/comunismo, acreditam que os alunos deveriam aprender que existem outros modos de produção, outras formas de economia para a sociedade. Fica então a questão sobre o que a sociedade quer formar? 


\section{O PAPEL QUE A FAMÍLIA TEM NO PROCESSO DE FORMAÇÃO}

Ao tratarmos do ensino de História escolar, podemos nos deparar com muitos problemas que ainda carecem de atenção, não só por parte dos discentes, como também do governo, da escola e dos pais dos alunos, os quais fazem parte da sociedade. A família é considerada, por muitos, como sendo a base da sociedade, a qual é a primeira instituição que a criança tem contato. Para o processo de socialização da criança, segundo Durkheim, ela também tem uma responsabilidade toda especial sobre o ensino educacional, em especial o ensino de história. Ou seja, cabe aos pais dar ao seu filho o modelo ou padrão social a ser seguido. A sociedade acaba estabelecendo padrões, segundo Weber (2006), os ditos tipos ideais, a serem internalizados pelos indivíduos para que estes sejam inseridos no meio social, a isso chamamos de socialização.

Dessa forma, a família é responsável pelo processo de socialização das crianças para que essas não sofram o isolamento social. Logo, cabe à sociedade estabelecer, segundo Durkheim (2007), os fatos sociais por meio da consciência coletiva. Os fatos sociais têm como características a coercitividade, a generalidade e a exterioridade. Assim, a sociedade exerce a coerção sobre todos os indivíduos, não dependendo da vontade dos mesmos, e isso só é possível graças à consciência coletiva, ou seja, às leis, regras e normas sociais. Em Max Weber (2006), poderíamos dizer que isso seria o tipo ideal para que pudéssemos ter uma sociedade coesa para se viver. Porém, caso a família deixe de cumprir seu papel no processo de socialização da criança, isso poderá lhe causar um fato social patológico, segundo Durkheim (2007).

Com isso, teríamos um problema fora da normalidade de uma dada sociedade, que é um organismo composto por suas partes, como as instituições sociais, as quais têm como finalidade, garantir o controle social. Isso poderia acarretar no isolamento social do indivíduo, uma vez que a pessoa foge dos padrões sociais, se diferenciando dos demais e se vendo como diferente, pode resolver se afastar do grupo por motivo de timidez, ou o próprio grupo poderá vê-lo como estranho, por não se adequar às normas, regras e leis sociais e assim isolá-lo, excluí-lo da sociedade e mais, caso esse indivíduo inflija as leis poderá sofrer o isolamento social como sanção de punição 
(cadeia) e em casos extremos, até a pena de morte (o que não é o caso no Brasil, ao menos legalmente). Por isso, cabe à primeira instituição social, à família, a responsabilidade de socializar a criança e ensiná-la que devemos aprender a conviver com as demais pessoas.

Depois da família, outra instituição social responsável pelo controle social, seria então, a educação (escola). Sendo assim, cabe à educação moldar as crianças, jovens e até mesmo adultos, conforme a consciência coletiva. A educação tem a incumbência de, não só ensinar a criança as matérias técnicas, como também, socializa-la, como pensava Sócrates sobre o bom mestre ser aquele que modela a alma de seus alunos, nos deixando a ideia ao menos duas coisas. A primeira é que, o professor tem o poder de moldar ou dar forma de pensamentos aos seus alunos e, assim, devemos conhecer e ensinar os processos históricos para nossos alunos, para que eles possam compreender toda a construção do meio em que vivem. E a segunda, conforme o pensamento de Sócrates, seria impossível o professor não doutrinar seu aluno ou haver uma escola sem partido, pois a formação do ser nada mais seria que uma escultura, uma construção do indivíduo para o meio social. E quando falo em construção, isso nos remonta aos pré-socráticos, quando da criação da "physis"[16] e do "nomos".[17]

Esses alunos que tem menos condições sociais, aqui não querendo entrar na questão de meritocracia, não tem tanta facilidade de alcançar um maior êxito nos estudos como aqueles que não precisam trabalhar para ter que se sustentar ou levar provimento para dentro de casa. Muitos de nossos alunos, jovens e adultos, têm que trabalhar durante o dia, e quando à noite, aqueles que querem conquistar uma melhor posição no mercado de trabalho, têm que ir à escola, mesmo cansados e pouco produtivos nos estudos.

Quando um professor de história ensina isso e outras coisas nesse sentido, é taxado de doutrinador e partidarista. Os professores agindo moralmente deveria ensinar, obviamente sem doutrinar, conforme os liberalistas entendem a escolarização, mas então surge a dúvida: o professor de matemática, ao ensinar os cálculos não estaria ensinando, direta ou indiretamente, o capitalismo? O que falar do professor de 
química, ou biologia e física? Não seriam eles também, desse ponto de vista, doutrinadores? Por qual motivo a sociedade tende a taxar de doutrinador somente os professores de humanas? Poderia haver escolarização ou educação que não seja de certa forma uma doutrinação?

Partindo dessas inquietações podemos dizer que, se uma sociedade impõe aquilo que deve ou não ser ensinado, isso também é encarado como doutrinação e uma doutrinação que controla os menos favorecidos em favor dos mais favorecidos. A diferença da doutrinação dos professores de humanas é que eles doutrinam para a libertação do sujeito em relação ao capitalismo exacerbado, enquanto que a doutrinação das exatas, biológicas e da natureza, doutrinam para que a classe dominante explore os menos favorecidos. Longe de querer aplicar conceitos socialistas ou comunistas aqui, até mesmo não é o objetivo como podemos observar na prática, que a escolarização tem suprimido a educação e focado apenas em formar trabalhadores para que o sistema capitalista possa sugar suas forças de trabalho, dando pouca ou nenhuma importância para as humanas, uma vez que na história sempre que um ditador sobe ao poder de uma dada nação, ele quer tirar ou tira as matérias escolares que abrem a mente dos alunos, para que esses sejam alienados.

Kant (1999) fala sobre a autonomia de pensamentos, onde cabe ao professor induzir seus alunos à emancipação da razão. Isso só é possível caso o professor queira dar aos seus alunos uma maioridade racional e isso depende de um profissionalismo ético e que seus alunos cooperem para que o processo de educação aconteça. Isso poderia ser entendido como que uma atividade da razão. Ao falarmos de razão, falamos aqui da faculdade inerente ao homem como uma de suas capacidades, senão a mais importante, como ser racional, como podemos ver, segundo Abbagnano:

Esse termo tem os seguintes significados:

1" Referencial de orientação do homem em todos os campos em que seja possível a indagação ou a investigação. Nesse sentido, dizemos que a R. é uma "faculdade" própria do homem, que o distingue dos animais. (ABBAGANO, 1990, p. 824) 
Essa razão é que impulsiona o homem às suas capacidades intelectivas[18] e cognitivas[19], levando esse ser a pensar, questionar e solucionar questões dos mais variados tipos. Diferenciar-se assim o homem dos demais animais, fazendo-o tomar conhecimento de sua existência no mundo e dessa maneira, poder escolher ou construir sua existência, da forma que sua razão o direciona. Aqui, entraria a participação do docente na formação do seu semelhante, uma espécie de altruísmo, onde o docente se entrega, se doa, para a formação dos discentes, ajudando estes a chegarem à sua formação racional como um ato de compartilhar. Conforme Paulo Freire, (1987) "Ninguém educa ninguém, ninguém educa a si mesmo, os homens se educam entre si, mediatizados pelo mundo".

Devido ao homem ser um animal racional, porém, frágil em seu nascimento, conforme nos coloca Mondin (1980), o homem é como um animal que precisa de ajuda para seu desenvolvimento. $\mathrm{O}$ homem nasce, em comparação com os demais animais, muito frágil e é extremamente dependente.

Pense-se, por exemplo no pintinho, que é realmente um animal jovem que já possui, desde o nascimento, uma forma completamente madura de sua figura, o que faz parecer uma edição rejuvenescida do animal adulto e lhe permite prover inteiramente suas necessidades; agora pense na criança recém-nascida, a qual é ainda por completo impotente e, sem os cuidados da mãe, está condenada a morrer dentro de poucos dias. (MONDIN, 1980, p. 31)

Assim como o homem carece de cuidados maternos ao nascer, esse mesmo precisa de cuidados de tutores para contribuir com o desenvolvimento de suas capacidades racionais. Esses tutores seriam então, dentro da instituição educação, os professores, os quais conduziriam seus alunos ao desenvolvimento intelectual, racional e cognitivo.

Aplicando aqui toda sua capacidade intelectual, os professores se dedicariam ao desenvolvimento dos seus alunos conduzindo-os ao amadurecimento racional, levando esses a terem capacidades para tomarem decisões adequadas de acordo com a exigência da situação, sempre levando em consideração e nunca se esquecendo das virtudes e da moral para a tomada de decisão. 
O elemento fisiológico que lhe permite atingir e também superar todas as várias especializações dos animais é o cérebro. Com esse órgão, que nele é superdesenvolvido em relação aos dos animais, ele compensa abundantemente a sua deficiência inicial. $O$ cérebro aparece aqui como fator de equilíbrio biológico. A compensação da carência com a formação do cérebro aparece como hipercompensação da inferioridade biológica constitucional. Sobre esta base é exigida para o homem especialização orgânico-funcional sobre o fundamento do seu cérebro. $O$ homem tornase, então, um ser especializado no cérebro. (MONDIN, 1980, p. 31).

Assim, o professor conduziria seus discentes ao amadurecimento racional, não deixando-os no simples senso comum, mas sim, investigativo, inquiridor, científico, libertando-os de uma escolarização e dando a eles a capacidade de andar pela trilha do conhecimento, tornando-se pessoas conscientes e críticas. De acordo com Jaeger (1994), afirma que toda educação é o resultado de uma consciência viva que rege a comunidade humana. Então, a educação consiste em dar forma à consciência da criança, jovem e até mesmo aos adultos, para que esses vivam de acordo com a realidade oferecida. E para tanto, ainda de acordo com Jaeger (1994), é preciso que a pessoa que tenha educação tenha também ética, moral e que seja virtuosa. Só então, essa pessoa poderá seguir e obedecer a norma que "rege a comunidade humana".

Então, quem poderia, de forma sistemática, dar vida a essa "consciência de uma norma que rege uma comunidade humana" melhor que os professores, que para isso foram formados ou ao menos deveriam ter sido?

\section{CONSIDERAÇÕES FINAIS}

Depois de realizada essa pesquisa bibliográfica podemos observar que desde sua sistematização na Grécia Antiga, a formação (educação e escolarização) sempre foi permeada por uma ideologia, pois essa serviu como instrumento de controle social para formar ou modelar o indivíduo conforme a vontade da sociedade anterior, a qual teria sido formada dentro daquilo que Durkheim (2007) chamou de consciência coletiva, ou daquilo que Weber (2006), chamou de tipo ideal, e hoje, mais do que nunca, essa instituição escola é usada para formar para o trabalho em detrimento da 
formação humana ou da cidadania. Isso é o que conhecemos de cultura, ou educação, ou tradição, palavras essas que são sinônimas.

Dessa forma, caberia à educação utilizar o conhecimento já herdado e evoluído pelas gerações anteriores e a partir dele, evoluir ainda mais e repassá-lo à geração posterior. Aqui estaria uma das várias utilidades da História para a educação e até mesmo para a escolarização, pois sendo o homem o animal especialista em cérebro, as ciências humanas o ajudaria a desenvolver ainda mais suas potencialidades. $O$ problema é que as humanas têm sido menosprezadas pelo governo e pela sociedade, os quais supervalorizam as ciências exatas e da natureza. Assim como colocado anteriormente, o que interessa para ambos é o status social.

Infelizmente essa busca pelo status social e o desprezo pela formação do cidadão, o qual seria uma das finalidades das ciências humanas, tem causado em nossa sociedade uma verdadeira estagnação da razão desse animal cerebral (homem). A própria escolarização doutrina nossas crianças a serem egoístas e quando muito, conhecer seus direitos, mas não ensinam conhecer e cumprir seus deveres. Estabelece-se uma forma de relação social pautada pelo conflito, pois, a partir do momento em que focamos em preparar trabalhadores e menosprezamos a formação do cidadão, como criaríamos uma consciência coletiva a não ser por meio de uma ditadura?

Por isso, para que haja uma sociedade mais coesa e para que possamos perpetuar nossa cultura sem estagná-la, é necessário a educação e não apenas a escolarização. O professor de História tem essa missão de buscar conhecer o passado, extrair o que de ruim e de bom esse passado tem a nos oferecer e repassar aos nossos alunos, dando a eles a capacidade de poderem evoluir, tanto no campo da ciência exatas e da natureza, como no campo das ciências humanas e assim, melhorar a cada dia a civilização

Conforme foi observado no decorrer da história, nunca houve uma sociedade que não doutrinasse ou uma educação que não tivesse partido. O que podemos concluir é que todo povo utilizaram da educação para modelar suas crianças, para que elas 
pudessem fazer parte da sociedade, perpetuando assim sua cultura e não deixando que essa, para alguns povos, não deixassem de existir. Logo, é impossível existir uma escola sem partido e professores que não doutrinem. Talvez o problema seja qual partido e o que ensinar, pois ao escolher um assunto e desprezar o outro o professor já está sendo partidário, e ao ensinar aquele assunto escolhido e não o outro o professor já está doutrinando. Por fim, seja para a escolarização ou para a educação, a escola toma partido e os professores doutrinam.

\section{BIBLIOGRAFIA}

ABBAGNANO, Nicola. Dicionário de filosofia. São Paulo: Martins Fontes, 2007.

BRASIL. Lei de diretrizes e bases da educação nacional, LDB. 9394/1996.

DURKHEIM, Émile. As regras do método sociologico. São Paulo: Martins Fontes, 2007.

DURKHEIM, Émile. Educação e Sociologia. Petrópolis, Rio de Janeiro: Vozes, 2011.

FREIRE, Paulo. Pedagogia do oprimido. Rio de Janeiro: Paz e Terra, 1987.

JAEGER, Werner Wilhelm. Paidéia: a formação do homem grego. São Paulo: Martins Fontes, 1994.

KANT, Immanuel. Sobre a pedagogia. Piracicaba: Editora Unimep, 1999.

MARX, Karl. Texto sobre a educação e ensino. Campinas, SP: Navegando, 2011.

MONDIN, Battista. O homem, quem ele é?. Elementos de antropologia filosófica. São Paulo: Paulus, 2005.

WEBER, Max. A "objeitividade" do conhecimento nas ciências sociais. São Paulo: Ática, 2006. 


\section{APÊNDICE - REFERÊNCIAS DE NOTA DE RODAPÉ}

3. Paideia grega: formação do homem tanto para a técnica para o trabalho como também, a moral para viver em sociedade.

4. Segundo Durkheim, é ligado por vínculos afetivos e tradicionais.

5. Segundo Durkheim, é um grupo ligado por interesses individuais e contemporâneo.

6. Conjunto de costumes, técnicas e valores características de um povo.

7. Técnicas necessárias para produzir alguma coisa.

8. Conjunto de hábitos essenciais para a vida em sociedade.

9. Aparência externa daquilo que ainda não foi internalizado.

10. Onde o sujeito aplica à ele mesmo as leis estabelecidas moralmente.

11. Crença no poder da ciência como sendo a única capaz de nos dar a verdade.

12. Senso comum.

13. Prestigio social, serem bem visto e respeitados.

14. Riqueza.

15. Poder de mando na sociedade.

16. Para os pré-socráticos, a physis é a natureza do homem, entendido como princípio de ação.

17. Era entendido como uma convenção, ou acordo, algo criado pelos homens.

18. Segundo Abbagnano (2007) O que não é sensível e não tem relação com o que é sensível. O I. é o divino ou aquilo que de divino há no homem. 
19. Modo de perceber e interpretar a si mesmo.

Enviado: Fevereiro, 2020.

Aprovado: Janeiro, 2021. 